Supporting Information for

\title{
Impact of Biofuel Blends on Black Carbon Emissions from a Gas Turbine Engine
}

Raju R. Kumal ${ }^{1}$, Jiawei Liu ${ }^{1}$, Akshay Gharpure ${ }^{1}$, Randy L. Vander Wal ${ }^{1}$, John S. Kinsey², Bob

Giannelli ${ }^{3}$, Jeffrey Stevens ${ }^{3}$, Cullen Leggett ${ }^{3}$, Robert Howard ${ }^{4}$, Mary Forde ${ }^{4}$, Alla ZelenyukImre $^{5}$, Kaitlyn Suski ${ }^{5}$, Greg Payne ${ }^{6}$, Julien Manin 6 , William Bachalo ${ }^{6}$, Richard Frazee ${ }^{7}$, Timothy B. Onasch ${ }^{8}$, Andrew Freedman ${ }^{8}$, David B. Kittelson ${ }^{9}$ and Jacob J. Swanson ${ }^{9}$

${ }^{1}$ The John and Willie Leone Family Department of Energy and Mineral Engineering and the EMS Energy Institute, Penn State University, University Park, PA 16802, USA. ${ }^{2}$ Retired (formerly US Environmental Protection Agency, Office of Research and Development, Center for Environmental Measurement and Modeling, Research Triangle Park, NC 27711, USA). ${ }^{3}$ US Environmental Protection Agency, National Vehicle and Fuel Emissions Laboratory (NVFEL), Ann Arbor, MI 48105, USA. ${ }^{4}$ US Air Force, Arnold Engineering Development Complex (AEDC), Arnold AFB, TN 37389, USA. ${ }^{5}$ US Department of Energy, Pacific Northwest National Laboratory (PNNL), Richland, WA 99352, USA. ${ }^{6}$ Artium Technologies Inc., Sunnyvale, CA 94085, USA. ${ }^{7}$ Singularity Scientific Consulting Services, LLC, Whitmore Lake, MI 48189, USA. ${ }^{8}$ Aerodyne Research Inc., Billerica, MA 01821, USA. ${ }^{9}$ Department of Mechanical Engineering, University of Minnesota, Minneapolis, MN 55455, USA

\section{Calculation of elemental carbon (EC)}

The elemental carbon (EC) content of filter-based particulate matter is measured for Jet-A and blended fuels across all engine powers. Highest EC for any given power follows: JetA > JetA30\% > JetA-70\% Camelina blends as shown in Figure 3a. The concentration of EC increases monotonically with engine power for each fuel, and the rate of increase depends on initial fuel aromatic content. Fuel aromatics seed nuclei formation and particle growth at early stages in more fuel-rich environments, resulting in higher soot concentrations. Higher fuel aromatic content results in stronger EC dependence on power. Other studies have referenced EC in terms of fuel $\mathrm{C} / \mathrm{H}$ ratio. ${ }^{1-2}$ With increasing power temperature increases as does turbulence. Temperature accelerates rates of soot formation and particle growth. Oppositely turbulence increases fuel-air mixing, lowering concentrations of nucleation and growth species while also decreasing the time for particle growth. Consequently, soot forming fuel-rich pockets are "mixed-out”. Nascent fuel 
aromatics are most sensitive to temperature for radical formation, the first step towards their reactive coagulation - representing particle nucleation and reactive addition - constituting particle growth. Forming resonance stabilized radicals, their activation occurs at lower temperatures than for other hydrocarbon components. Higher aromatic concentrations then lead in turn to higher radical concentrations and stronger dependence of rates upon temperature by a concentration effect, different than an activation energy effect.

Additionally, the concentration of EC increases with increasing aggregate size for any
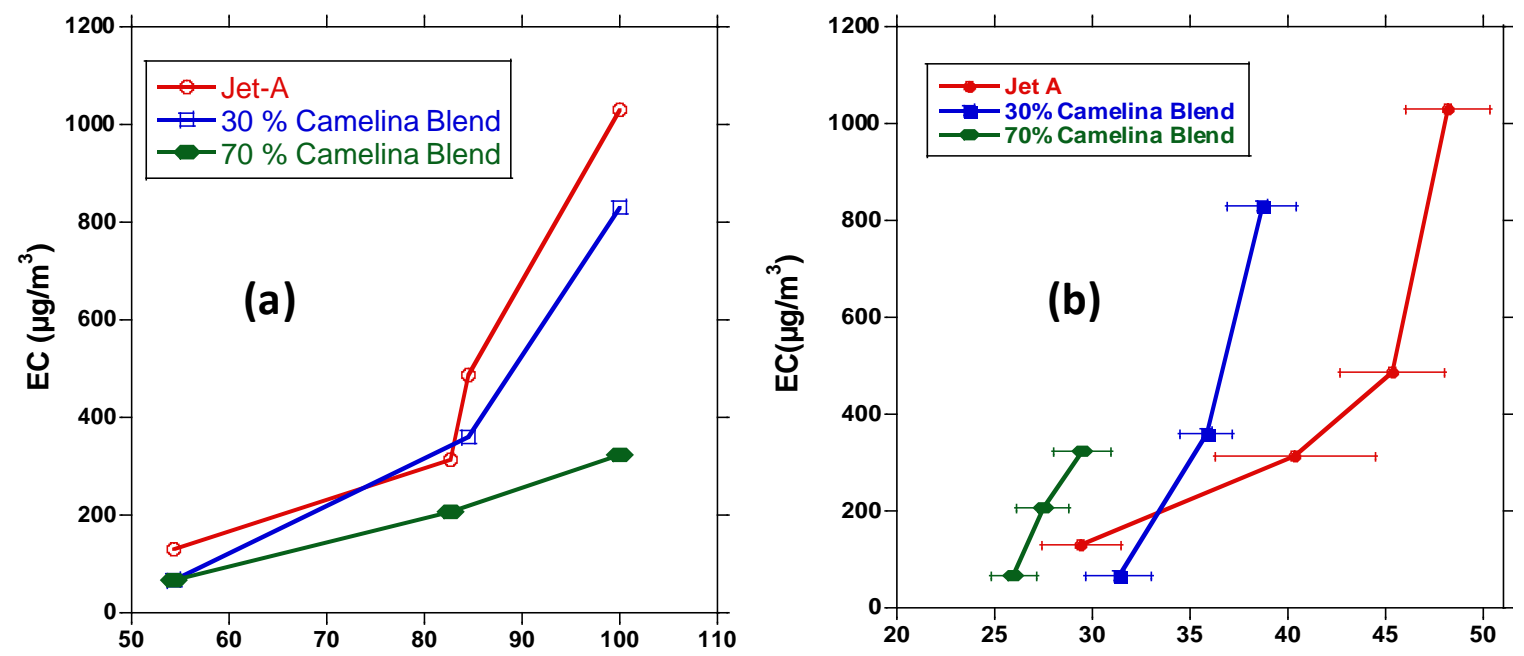

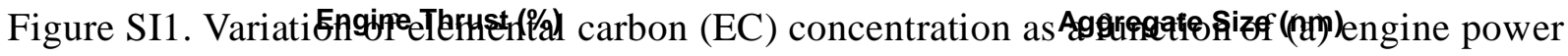
and (b) aggregate size across three different fuels; Jet A, 30\% Camelina blend and 70\% Camelina blend.

given fuel. Fuel carried aromatics govern initial soot formation: particle nucleation and growth. Moreover, these processes can occur at lower temperatures and earlier times due to the resonance stabilized radicals formed from the nascent aromatics. Early formation in turn fosters growth in fuel-rich regions with higher $\varphi$ further accelerating particle nucleation and growth by mass action. Since mass scales with aggregate size, a similar dependence of EC upon aggregate size would be 
expected, across all fuels regardless of aromatic content. However, initial fuel aromatic content does determine the range of aggregate size and for this reason, ultimately maximum EC value. The intriguing aspect is this apparent relationship between a microscopic quantity, aggregate size and a macroscopic measure of EC concentration.

Linear dependencies were observed for aggregate size with combustor thrust. Highest slope for Jet-A $(0.45, R=0.977)$, followed by the $30 \%$ blended fuel $(0.282, R=0.976)$ with lowest dependence for the $70 \%$ blended fuel $(0.0875, \mathrm{R}=0.997)$. Fringe analyses for curvature differences between the fuels reveal differences greater than $10 \%$ across categories. Corresponding CHEMKIN calculations predict greater than a 10-fold increase in C5/C6 mole ratio, dependent on $\emptyset$. Between 55 and 100\% thrust levels, a monotonic relation is observed between EC $\left(\mu \mathrm{g} / \mathrm{m}^{3}\right)$ and thrust with nearly a 5-fold difference between Jet-A and its blend with 70\% camelina at the highest level. Further studies are needed to assess the commonality of these results across more modern turbofan engines.

Table SI1 shows the hydrogen content of each fuel type. Similarly, Table SI2 shows a thrust versus fuel flow rate (gallons per minute, $\mathrm{g} / \mathrm{m}$ ). Power levels were measured and converted to thrust as percentage of full scale thrust (100\%).

Table SI1. Typical properties of fuels used in the J85 engine for VARIAnT 4.

\begin{tabular}{|c|c|}
\hline Fuel type & Hydrogen content \\
\hline Jet-A & 14.05 \\
\hline 30\% Camelina Blend & 14.60 \\
\hline 70\% Camelina Blend & 15.31 \\
\hline
\end{tabular}


Table SI2. Fuel flow rate (g/min) at various normalized engine thrusts.

\begin{tabular}{|c|c|c|}
\hline Fuel Type & Thrust (\%) & $\begin{array}{l}\text { Fuel flow rate (gram/min) at } \\
\text { temperature } 77^{\circ} \mathrm{F}\end{array}$ \\
\hline Jet A & 3.9 & 3902.3 \\
\hline Jet A & 23.5 & 7509.5 \\
\hline Jet A & 54.3 & 9715.8 \\
\hline Jet A & 74.4 & 11569.1 \\
\hline Jet A & 82.7 & 12595.4 \\
\hline Jet A & 84.5 & 16228.3 \\
\hline Jet A & 100.0 & 17214.2 \\
\hline 30\% Camelina blend & 3.8 & 3639.7 \\
\hline 30\% Camelina blend & 54.3 & 9522.1 \\
\hline 30\% Camelina blend & 84.5 & 15674.6 \\
\hline 30\% Camelina blend & 100.0 & 16907.4 \\
\hline 70\% Camelina blend & 54.3 & 9719.0 \\
\hline 70\% Camelina blend & 82.7 & 15062.8 \\
\hline 70\% Camelina blend & 100.0 & 17125.3 \\
\hline
\end{tabular}




\section{References}

1. Saffaripour, M.; Thomson, K. A.; Smallwood, G. J.; Lobo, P., A Review on the morphological properties of non-volatile particulate matter emissions from aircraft turbine engines. J. Aerosol Sci. 2019, 139, 105467.

2. $\quad$ Schripp, T.; Anderson, B.; Crosbie, E. C.; Moore, R. H.; Herrmann, F.; Oßwald, P.; Wahl, C.; Kapernaum, M.; Köhler, M.; Le Clercq, P., Impact of alternative jet fuels on engine exhaust composition during the 2015 ECLIF ground-based measurements campaign. Environ. Sci. Technol. 2018, 52, 4969-4978. 